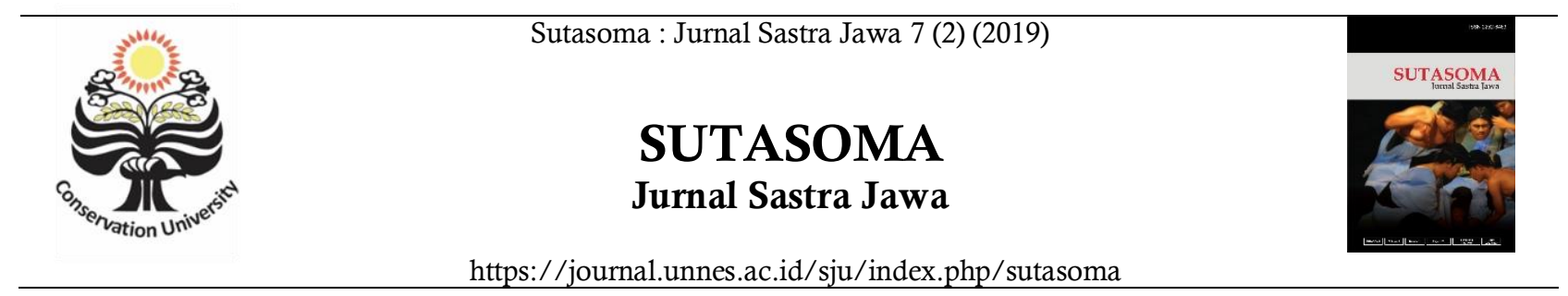

https://journal.unnes.ac.id/sju/index.php/sutasoma

\title{
Pemertahanan Bahasa Jawa Dialek Tegal dalam Kumpulan Cerkak Tegalan Warung Poci Karya Dr. Maufur
}

\author{
Siska Aditya Ningtyas ${ }^{1}$, Eka Yuli Astuti, S.Pd.,M.A. ${ }^{2}$, Drs. Widodo, M.Pd. ${ }^{3}$ \\ 1,2,3Jurusan Bahasa dan Sastra Jawa, Fakultas Bahasa dan Seni, Universitas Negeri Semarang, Indonesia \\ Corresponding Author: siskaaditya@gmail.com
}

\begin{abstract}
Abstrak
Penelitian ini bertujuan untuk mendeskripsikan bentuk-bentuk pemertahanan bahasa Jawa dialek Tegal dalam kumpulan cerkak Tegalan Warung Poci karya Dr. Maufur. Penelitian ini menghasilkan bentuk-bentuk pemertahanan bahasa Jawa dialek Tegal, yaitu bentuk pemertahanan bahasa aktif dan bentuk pemertahanan bahasa pasif dengan mencatatnya ke dalam kartu data. Bentuk pemertahanan bahasa aktif berupa pemakaian kata-kata berdialek Tegal yang sudah jarang digunakan dalam kehidupan sehari-hari meliputi: bentuk kata dasar, bentuk kata berimbuhan, bentuk reduplikasi, bentuk reduplikasi berimbuhan, dan bentuk tembung saroja. Bentuk pemertahanan bahasa pasif menunjukkan adanya pemakaian unsur bahasa asing dalam penggalan kalimat berdialek Tegal yang meliputi pemakaian kata dasar, kata berimbuhan, frasa, reduplikasi, reduplikasi berimbuhan, dan penerjemahan kata berbahasa asing (bahasa Indonesia dan bahasa Inggris) ke dalam dialek Tegal yang merujuk pada kekeliruan bahasa atau interferensi. Penerjemahan tersebut menunjukkan bahwa dialek Tegal bersifat dinamis karena memunculkan unsur bahasa asing dalam penggalan kalimatnya dengan tujuan agar tercipta kalimat yang komunikatif dan memberi warna berbeda pada penggunaan dialek Tegal.
\end{abstract}

Kata kunci: pemeliharaan bahasa; Dialek tegal; Warung Poci

\begin{abstract}
This study aims to describe the forms of retention of the Javanese language in the Tegal dialect in the cerkak of Tegalan Warung Poci by Dr. Maufur. This research produces forms of retention of Javanese Tegal dialect, namely forms of active language retention and forms of passive language retention by recording it on a data card. Forms of active language retention in the form of the use of words with Tegal dialect that are rarely used in daily life include: basic word forms, forms of affixed words, forms of reduplication, forms of reduplication with implications, and forms of clay saroja. The passive language retention form shows the use of foreign language elements in fragments of Tegal dialect which includes the use of basic words, affixed words, phrases, reduplication, affixed reduplication, and translation of foreign language words (Indonesian and English) into the Tegal dialect that refers to language error or interference. The translation shows that the Tegal dialect is dynamic because it raises elements of the foreign language in the sentence fragment with the aim of creating communicative sentences and giving a different color to the use of the Tegal dialect.
\end{abstract}

Keyword: language maintenance; Tegal dialect; Warung Poci

(C) 2019 Universitas Negeri Semarang

p-ISSN 2252-6463 e-ISSN 2686-5408 
Siska Aditya N., dkk/Sutasoma 7 (2) (2019)

\section{PENDAHULUAN}

Kumpulan cerkak Tegalan Warung Poci mulanya merupakan tajuk dalam surat kabar Suara Merdeka, rubrik Pantura. Tajuk Warung Poci terbit satu minggu sekali, di hari Senin, ditulis oleh Yono Daryono dan Dr. Maufur. Namun, hanya karya Dr. Maufur yang dijadikan kumpulan cerkak Tegalan Warung Poci. Kumpulan cerkak ditulis sejak tahun 2011 sampai tahun 2014. Dalam kumpulan cerkak Warung Poci terdapat 71 (tujuh puluh satu) judul dan 234 halaman ditulis dalam dialek Tegal.

Hal tersebut mencerminkan bahwa karya sastra dapat menjadi salah satu alat pemertahanan bahasa Jawa termasuk dialek Tegal. Meskipun di dalamnya terdapat bahasa Indonesia yang ditulis dengan tidak sengaja karena latar belakang sosial yang beragam. Hadiati (2013) menyebutkan bahwa terdapat bentuk pemertahanan bahasa aktif dan bentuk pemertahanan bahasa pasif. Penelitian inipun mendeskripsikan kedua bentuk pemertahanan bahasa tersebut.

Penelitian ini penting karena dalam bentuk pemertahanan bahasa ditemukan beberapa hal yang merujuk pada gejala pergeseran bahasa. Salah satunya adanya bentuk pemertahanan bahasa pasif. Selain itu, kenyataan bahwa bahasa Indonesia menjadi bahasa pengantar dalam ranah pendidikan dan pemerintahan dengan alasan lebih komunikatif digunakan juga menjadi suatu ancaman bagi keberadaan dialek Tegal. Fishman dalam

Willian (2010) menyatakan bahwa dalam penggunaan bahasa terdapat konteks-konteks sosial yang melembaga (institutional context) yang disebut ranah, dimana lebih cocok untuk digunakan ragam atau bahasa tertentu daripada ragam atau bahasa lain. Apalagi jika diperhatikan bahwa pembelajaran bahasa Jawa di sekolah-sekolah juga tidak menggunakan dialek Tegal sebagai bahasa pengantar dalam pembelajaran serta dalam materi, semakin membuat keberadaan dialek Tegal terancam punah. Namun, justru karena itulah dialek Tegal justru harus diangkat demi terwujudnya pemertahanan bahasa Jawa dialek Tegal sehingga dapat meminimalisir terjadinya pergeseran bahasa bahkan kepunahan bahasa. Wijana (2005) bahwa bahasa daerah merupakan alat penghubung intraetnis yang merupakan lambang semangat kedaerahan yang harus dipelihara keberadaannya sebagai pendukung dan pemerkaya bahasa Jawa standar. Tujuan penelitian untuk mendeskripsikan bentuk-bentuk pemertahanan bahasa Jawa dialek Tegal yang terdapat dalam kumpulan cerkak Tegalan Warung Poci karya Dr Maufur.

\section{METODE PENELITIAN}

Penelitian ini menggunakan pendekatan teoretis berupa pendekatan sosiolinguistik dan pendekatan metodologis berupa pendekatan deskriptif kualitatif. Azwar (2012: 6) menyatakan penelitian deskriptif melakukan analisis hanya sampai pada taraf deskriptif, yaitu menganalisis dan menyajikan fakta secara sistematik sehingga dapat lebih mudah untuk difahami dan disimpulkan.

Data penelitian berupa penggalan kalimat berdialek Tegal dalam kumpulan cerkak Tegalan Warung Poci. Metode pengumpulan data dengan metode simak, teknik sadap dan catat. Setelah tahap pengumpulan data kemudian dilakukan tahap klasifikasi data. Data disortir kemudian dikelompokkan menjadi kelompok bentuk pemertahanan bahasa aktif dan kelompok bentuk pemertahanan bahasa pasif. Selanjutnya tahap transkripsi data dari dialek Tegal ke dalam bahasa Indonesia dan transkripsi secara linguistik. Instrumen penelitian adalah kartu data yang digunakan untuk mencatat data-data yang telah dianalisis. Penelitian ini menggunakan dua teknik analisis data (ekletik), 
yaitu teknik analisis isi, dan teknik analisis data model Miles \& Huberman, terdapat enam tahapan analisis isi, yaitu uniting (pengunitan), reducing (pengurangan), sampling (penyamplingan), recording (perekaman), inferring (simpulan), dan narrating (penarasian).

\section{HASIL DAN PEMBAHASAN}

1. Bentuk Pemertahanan Bahasa Aktif

Bentuk pemertahanan bahasa aktif ditunjukkan melalui pemakaian kata yang sudah jarang digunakan dalam kehidupan sehari-hari, meliputi: pemakaian bentuk kata dasar, kata berimbuhan, reduplikasi, reduplikasi berimbuhan, dan tembung saroja.

a. Bentuk kata dasar

“.... Krungu pitakonan sing radan aneh, jarene

Pak Thomas ngrajug kaget. ...."

[.... Kruyu pitakonan sin radan anch, jarene

Pa? Thomas yrajug kaget. ....]

Terjemahan:

'.... Mendengar pertanyaan yang agak aneh, Pak Thomas terkejut kaget. ...' (Data no. A 1-04, 5/p. 3/hal. 36)

Kata ngrajug merupakan kata dasar dalam dialek Tegal yang menunjukkan suatu kebanggaan penulis dalam berbahasa dialek Tegal. Kata ngrajug lebih sering digunakan oleh masyarakat Tegal berusia tua.

b. Bentuk kata berimbuhan.

“.... Awit bocah sing blenyikan apa maning sing kaplak tuwa lata, sing dosane sekandang banteng. ...."

[.... Awit bocah sin bləñikan apa manin sin kaplak tuwa lata, sin dosane səkandan bantey. ....]

Terjemahan:

‘... Mulai dari anak kecil apalagi orang yang sudah dewasa, yang dosanya sebesar kandang banteng. ...' (Data no. B 1-1, 43/p. 8/hal. 150)

Kata blenyikan berasal dari kata blenyik, sufiks atau panambang -an. Kata blenyikan memiliki makna yang sepadan dengan penyebutan anak burung, piyikan. Kata blenyikan sudah jarang digunakan, muncul sebagai suatu wujud ingatan penulis tentang penggunaan kata tersebut.

c. Bentuk reduplikasi.

“... Ana sing bisa gemuyu merga krasa lucu, ana sing mung bisane тиси-тиси..."

[.... Ana sin bisa gəmuyu mərga krasa lucu, ana sin mun bisane mucu-mucu. ....]

Terjemahan:

'.... Ada yang bisa tertawa karena merasa lucu, ada yang bisanya hanya mucu-mucu.

...' (Data no. C 1-01, 1/p. 1/hal. 23)

Kata muсu-mucu dalam kutipan di atas dipilih karena kata tersebut lebih sesuai digunakan dalam konteks kalimat jika dibandingkan dengan kata jengkel yang maknanya 'marah' atau kata mrengut yang maknanya 'cemberut'. Padahal diksi yang dibutuhkan dalam kalimat tersebut adalah yang menunjukkan pada ekspresi marah sambil menggerutu.

d. Bentuk reduplikasi berimbuhan "Senajan nyorot langsung, tetep bae penonton sing teka marani lapangan akeh nemen, sesek del-delan, stadion pan ora muat. ...."

[Sənajan ñorot laysuy, tətəp bae pənonton sin təka marani lapayan akeh nəmən, səsək də1dəlan, stadion pan ora muat. ....]

Terjemahan:

'Meskipun disiarkan secara langsung, namun tetap saja banyak sekali penonton yang datang langsung ke lapangan, sangat ramai hingga 
berdesak-desakan, stadion seperti sudah tidak muat lagi...' (Data no. D 1-01, 3/p. 2/hal. 30)

Kata del-delan berasal dari reduplikasi kata del mendapatkan sufiks atau panambang -an yang berarti 'berdesak-desakan'. Penulis ingin memperkenalkan kata berdialek Tegal del-delan yang sudah jarang digunakan. Masyarakat Tegal lebih sering menggunakan kata sesek-sesekkan dalam percakapan sehari-hari. Kata del-delan seharusnya secara fonetis ditulis [ḍəl-dəlan] sesuai pelafalan dialek Tegal yang tidak mengenal fonem /d/. Akan tetapi, karena dialek Tegal tidak memiliki tata bahasa yang baku, maka semua kata yang mengandung fonem / ditulis dengan fonem $/ \mathrm{d} /$.

e. Bentuk tembung saroja

“.... Angger konangan deweke ndean ngomong.

"Puas ladas, kapoke kapan? Mulane gen aja sokan ngerjani wong." ...."

[.... Aygər konayan deweke ndean yomon. "Puas ladas, kapoke kapan? Mulanegen, aja sokan yərjani woy." ....]

Terjemahan:

'....Kalau ketahuan beliau mungkinberkata.

"Kasihan, kapan kapoknya? Makanya, jangan sering mengganggu orang." ...' (Data no. E 1-01, 9/p. 12/hal. 51)

Puas ladas termasuk ke dalam tembung saroja merupakan wujud kebanggaan berbahasa penulis pada dialek Tegal. Puas ladas digunakan untuk menunjukkan makna sangat pada kata puas yang dalam Bahasa Indonesia, berarti 'kasihan'. Puas ladas merujuk pada kata-kata umpatan yang bertujuan untuk mengejek. Puas ladas seharusnya secara fonetis ditulis [puas laḍas] sesuai pelafalan dialek Tegal yang tidak mengenal fonem /d/. Akan tetapi, karena dialek Tegal tidak memiliki tata bahasa yang baku, maka semua kata yang mengandung fonem /ḍ/ ditulis dengan fonem /d/.

\section{Bentuk Pemertahanan Bahasa Pasif}

Bentuk pemertahanan bahasa pasif merupakan bentuk pemertahanan bahasa yang ditandai dengan penggunaan bahasa Jawa secara dominan namun mengandung satu unsur bahasa asing di dalamnya (Hadiati, 2013). Penggunaan unsur bahasa asing ini ditunjukkan melalui bentuk kata dasar, bentuk kata berimbuhan, bentuk frasa, bentuk reduplikasi, bentuk reduplikasi berimbuhan, dan bentuk penerjemahan kata-kata berbahasa asing (bahasa Indonesia dan bahasa Inggris) ke dalam dialek Tegal yang merujuk pada kekeliruan bahasa atau interferensi.

a. Bentuk kata dasar

“... Buktine langka siji-sijiya kursi sing kosong, kabeh ana sing njagongi, ora lanang ora wadon, ora bocah ora wong tuwa, tumplek blek nang stadion."

[.... Buktine lanka siji-sijiya kursi sin koson, kabeh ana sin njagoni, ora lanay ora wadon, ora bocah ora woy tuwa, tumplək blək nay stadion.] Terjemahan:

'.... Buktinya tak ada satu pun kursi yang kosong, semua ada yang menempati,tidak lakilaki tidak perempuan, tidak anak-anak tidak orang dewasa, jadi satu di stadion." (Data no. A 2-04, 3/p. 2/hal. 30)

Kata 'kursi' merupakan kata dasar dalam bahasa Indonesia. Penggunaan kata 'kursi' dalam kutipan di atas menunjukkan bahwa penulis memiliki latar belakang sosial yang beragam, sehingga secara tidak sengaja memasukkan unsur bahasa Indonesia ke dalam penggalan kalimat di atas. Kata 'kursi' dalam dialek Tegal yaitu korsi. Perbedaan satu fon dalam kata 'kursi' dan korsi menjadikannya samar. Padahal perbedaan satu fon tersebut menunjukkan perbedaan asal bahasa. Kata 
'kursi' merupakan bahasa Indonesia, sedangkan kata korsi merupakan dialek Tegal. Selain kata korsi, dialek Tegal juga memiliki kosakata yang sepadan artinya dengan kata 'kursi', yaitu kata jengkok.

b. Kata berbahasa asing dalam bentuk kata berimbuhan

“.... Sing nggawa acara ngobrol karo komentator sing gawene moyoki, maido,nyalahna, tapi ya sepisanpisan ngalem. ...."

[.... Sin ygawa acara yobrol karo komentator sin gawene moyoki, maido, ñalahna,tapi ya səpisanpisan yaləm. ....]

Terjemahan:

‘... Pembawa acara mengobrol dengan komentator yang sukanya mengejek, menyalahkan, tetapi sekali-kali memuji. ...' (Data no.B 2-03, 3/p. 6/hal. 31)

Penggunaan kata 'ngobrol' yang merupakan pemendekan kata 'mengobrol' dalam bahasa Indonesia memberikan warna yang berbeda pada penggalan kalimat di atas. Masyarakat Tegal biasanya menggunakan kata kandha atau ndopok untuk menyatakan makna 'mengobrol', namun dalam kutipan di atas pemilihan kata 'ngobrol' menciptakan makna yang lebih formal daripada menggunakan kosakata dialek Tegal.

c. Kata berbahasa asing dalam bentuk frasa.

“.... Tapi enyong nang batin, yen kaya kuwe syukur lah, dadi nang antarakita langka pitnah."

[... Tapi əñon naך batin, yen kaya kuwe syukur lah, dadi nay antara kita lanka pitnah.]

Terjemahan:

'.... Tetapi dalam hati saya, seperti itu ya bagus lah, jadi di antara kita tidak ada fitnah.' (Data no. C 2-01, 13/p. 10/hal. 63)

Penggunaan frasa 'nang antarane kita' merupakan percampuran dua unsur bahasa, yaitu bahasa Indonesia dan dialek Tegal. Kata nang dan sufiks - $e$ dalam kata 'antarane'dalam penggalan kalimat di atas berfungsi sebagai penyamar agar frasa 'nang antarane kita' terlihat seperti frasa berdialek Tegal. Padahal apabila ditulis dalam dialek Tegal frasa tersebut menjadi antarane dewek. Namun adanya frasa 'nang antarane kita' membuat warna baru dalam dialek Tegal.

d. Penggunaan unsur berbahasa asing dalam bentuk reduplikasi.

“... Obrolane soal Tegal saiki, nganggone bahasa Tegal, sampai-sampai wongrestorasi sing akehe wong Semarang pada bingung dewek. ...."

[.... Obrolane soal Təgal saiki, naygone bahasa Təgal, sampai-sampai woyrestorasi sin akche woy Səmaran pada binun dewek. ....]

Terjemahan:

‘... Obrolannya tentang Tegal sekarang, menggunakan bahasa Tegal, sampai-sampai petugas restorasi yang kebanyakan adalah orang Semarang kebingungan sendiri." (Data no. D 201, 24/p. 10/hal. 95)

Penggunaan kata ulang 'sampai-sampai' dalam kutipan di atas menunjukkan bahwa penulis memiliki keberagaman latar belakang sosial. Padahal dialek Tegal memiliki kosakata yang maknanya sama dengan kata 'sampaisampai', yaitu kata nganti.

e. Penggunaan kata berbahasa asing dalam bentuk reduplikasi berimbuhan

"....Wektu bis mandeg, wong-wong wadon sing dodolan ngucap barang dagangane komplit, disitdisitan kaya balapan, keras-kerasan, saya suwe nyebut aran barang dagangane disingkat-singkat. ...."

[.... Wəktu bis mandəg, won-won wadon sin dodolan jucap baran daganane komplit, disit- 
disitan kaya balapan, kəras-kərasan, saya suwe ñəbut aran baran daganane disinkat-sinkat. ....] Terjemahan:

'.... Ketika bus berhenti, wanita-wanita yang berjualan meneriakkan barang dagangannya secara komplit, dulu-duluan seperti balapan, keras-kerasan, semakin lama menyebut barang dagangannya disingkat-singkat. ...' (Data no. E 2-01, 26/p. 9/hal. 101)

Kata 'keras-kerasan' berasal dari reduplikasi kata 'keras' mendapatkan sufiks -an. Penggunaan kata ulang 'keras-kerasan' dalam kutipan di atas menunjukkan beragamnya latar belakang sosial penulis. Padahal dialek Tegal memiliki kosakata yang maknanya sama dengan kata 'keras-kerasan', yaitu kata rosa-rosanan. Namun pemilihan kata 'keras-kerasan' dalam penggalan kalimat di atas dimaksudkan agar pesan dapat dikomunikasikan dengan baik.

f. Penggunaan unsur bahasa asing dalam bentuk penerjemahan kata berbahasa asing ke dalam dialek Tegal yang merujuk pada kekacauan bahasa atau interferensi.

“.... Lagi ngobrol ngalor ngidul wong telu, ana suara kring telpon ceketem utawatelpon genggam saka njero kamar. ..."

[... Lagi nobrol yalor nidul won təlu, ana suara krin telpon cəkətəm utawa telpongəygam saka njəro kamar. ....]

Terjemahan:

'.... Sedang ngobrol ke sana ke mari bertiga, ada suara kring telepon genggamdari dalam kamar.

...' (Data no. F 2-07, 25/p. 3/hal. 96)

Kutipan di atas menunjukkan adanya penerjemahan frasa berbahasa Indonesia 'telepon genggam' menjadi frasa berdialek Tegal telpon ceketem. Kata telpon ceketem dalam kutipan di atas termasuk ke dalam interferensi pada bidang sintaksis, yaitu digunakannya struktur bahasa Indonesia dalam proses penerjemahan kata 'Telepon genggam' dalam dialek Tegal.

\section{SIMPULAN}

Bentuk pemertahanan bahasa aktif dalam kumpulan cerkak Tegalan Warung Poci ditunjukkan melalui pemakaian kata-kata berdialek Tegal yang sudah jarang digunakan dalam kehidupan sehari-hari yang meliputi pemakaian dalam bentuk kata dasar, kata berimbuhan, reduplikasi kata, reduplikasi kata berimbuhan, dan tembung saroja. Bentuk pemertahanan bahasa pasif dalam kumpulan cerkak Tegalan Warung Poci ditunjukkan melalui penggunaan bahasa asing pada kata dasar, kata berimbuhan, frasa, reduplikasi, reduplikasi berimbuhan, dan penerjemahan kata berbahasa asing (bahasa Indonesia dan bahasa Inggris) ke dalam dialek Tegal yang merujuk pada kekeliruan bahasa atau interferensi. Hasil penelitian menunjukkan bahwa bentuk pemertahanan bahasa aktif lebih banyak jumlahnya dibandingkan dengan bentuk pemertahanan bahasa pasif. Gejala pergeseran bahasa tersebut ditunjukkan melalui: hilangnya fonem /ḍ/ digantikan dengan fonem /d/ dalam penulisannya. Namun dalam pelafalannya masih menggunakan fonem /ḍ/; terdapat unsur bahasa asing (dalam hal ini bahasa Indonesia dan bahasa Inggris) dalam penggalan kalimat berdialek Tegal; dan terjadi proses penerjemahan kata berbahasa asing ke dalam dialek Tegal yang menggunakan struktur bahasa asing yang bersangkutan.

\section{DAFTAR PUSTAKA}

Azwar, Syaifudin. 2012. Metode Penelitian. Yogyakarta: Pustaka Pelajar.

Chaer, Abdul. 2010. Sosiolinguistik Perkenalan Awal. Jakarta: Rineka Cipta

Hadiati, Puji.2013.Pergeseran dan Pemertahanan Bahasa Jawa pada Komunitas Band di Studio Orion Kabupaten Kebumen. Jurnal Pendidikan, Bahasa, Sastra, dan 
Siska Aditya N., dkk/Sutasoma 7 (2) (2019)

Budaya Jawa Universitas Muhammadiyah Purworejo 03 (06) 12-17.

Miles. B. Matthew, A. Michael Huberman. 2007. Analisis Data Kualitatif. Trans. Tjetjep Rohandi Rohidi. Jakarta: UI Press.

Moleong, Lexy J. 2009. Metodologi Penelitian Kualitatif. Bandung: Remaja Rosdakarya Offset.

Sudaryanto. 1993. Metode dan Aneka Teknik Analisis Bahasa. Yogyakarta: Duta Wacana University Press.

Wijana, I Putu. 2005. Pemertahanan Dialek Banyumas terhadap Dominasi Dialek Solo-Jogja. Jurnal Humaniora 17 (2) 154-159.

Wilian, Sudirman. 2010. Pemertahanan Bahasa dan Kestabilan Kedwibahasaan Pada Penutur Bahasa Sasak di Lombok. Jurnal Linguistik Indonesia 28 (1) 23-39. 